\title{
Seismic Vulnerability Maps of Ratu Agung District, Bengkulu City, Indonesia
}

\author{
Mase, L.Z. ${ }^{*}$
}

\begin{abstract}
During the $8.6 \mathrm{M}_{\mathrm{w}}$ Bengkulu-Mentawai Earthquake Ratu Agung District was identified as an impacted area. This paper aims to deliver the seismic vulnerability based on geophysical observation. This study was initiated by performing the ambient noise measurement to obtain the geophysical characteristic, such as amplification and predominant frequency. Furthermore, the vulnerability index analysis was performed from the geophysical information collected from the investigation. To observe the tendency of ground damage during the earthquake, ground damages analysis is also performed. All results are depicted into the microzonation maps. The results showed that the amplification and predominant frequency on site are generally ranging from 3 to 5 and 5 to $8 \mathrm{~Hz}$, respectively. The seismic vulnerability index in study area is up to $10^{-3}$. The results showed that during the Bengkulu-Mentawai Earthquake, the investigated sites could be possible to undergo crack settlement which can trigger massive sand boiling in the study area.
\end{abstract}

Keywords: Bengkulu-mentawai earthquake; seismic vulnerability; amplification; predominant frequency.

\section{Introduction}

A strong earthquake occurred on September 12, 2007, which was later known as the BengkuluMentawai Earthquake, has raised many questions to the geotechnical engineers and geophysicists. The main issues related to this event are liquefaction phenomenon along coastal area [1], the reliability of seismic design code [2], and the seismic vulnerability and microzonation maps for the seismic hazard mitigation in Bengkulu [3]. One of the areas in Bengkulu City that was undergoing the significant damage during the Bengkulu Mentawai Earthquake in 2007 was Ratu Agung District (Figure 1). Several researchers such as Mase [1], Farid and Hadi [3] and Refrizon et al. [4] reported that geotechnical damages could occurred during the earthquake in this region.

Several researchers, such as Mase [1,2,5], Farid and Hadi [3], Refrizon et al. [4], Mase and Somantri [6], and Mase [7] had studied the earthquake impact and another related phenomenon called liquefaction damage during the Bengkulu-Mentawai Earthquake on September 12, 2007.

\footnotetext{
1, Department of Civil Engineering, Faculty of Engineering, University of Bengkulu, J. WR. Supratman, No. 2, Kandang Limun 38371, Muara Bangkahulu, Bengkulu City, INDONESIA.

*Corresponding author; email: Imase@unib.ac.id
}

Note: Discussion is expected before November, $1^{\text {st }} 2019$, and will be published in the "Civil Engineering Dimension", volume 22, number 1, March 2020.

Received 06 May 2019; revised 23 September 2019; accepted 09 October 2019.
Mase [5] studied the characteristic of earthquake in Bengkulu City and reached a conclusion that during the Bengkulu-Mentawai Earthquake, the damage intensity expressed by the Modified Mercalli Intensity (MMI) is about scale IX. Mase and Somantri [6] studied the liquefaction damage along coastal area of Bengkulu City due to the Bengkulu-Mentawai Earthquake. The results of that study showed that along coastal area of Bengkulu City is vulnerable to undergo liquefaction during the earthquake. Mase [7] performed a finite element analysis to observe the excess pore pressure at sand layers along coastal area of Bengkulu during the Bengkulu-Mentawai Earthquake. The result of Mase [7] study exhibited that shallow sand layers along coastal area of Bengkulu City is very vulnerable to undergo liquefaction during the Bengkulu-Mentawai Earthquake in 2007. Mase [1] examined one-dimensional seismic ground response analysis to observe the liquefaction potential along coastal area of Bengkulu City. In that study, Mase [1] mentioned that at shallow depth, the excess pore water pressure ratio $\left(r_{u}\right)$ had reached and exceeded the liquefaction threshold. Mase [2] performed a seismic ground response analysis to the soil sites along coastal area of Bengkulu City. Mase [2] suggested that the ground amplification during the Bengkulu-Mentawai Earthquake was relatively high. In addition, Mase [2] mentioned that during the Bengkulu-Mentawai Earthquake, the resonance phenomenon could be more on low to medium high-rise building. In general, the previous studies focused on the liquefaction potential and the performance of seismic design during the BengkuluEarthquake only for specific sites in Bengkulu, 
especially along coastal area of Bengkulu, whereas a detail study related to seismic vulnerability for a specific region has not been performed yet. However, the previous studies had reached a preliminary conclusion that Bengkulu City could undergo the seismic damage during The Bengkulu-Mentawai Earthquake.

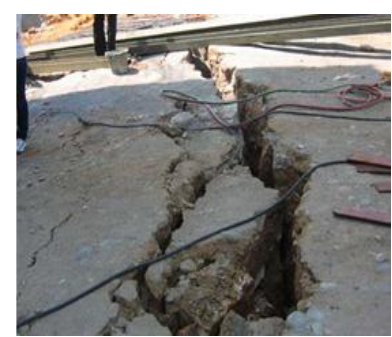

(a)

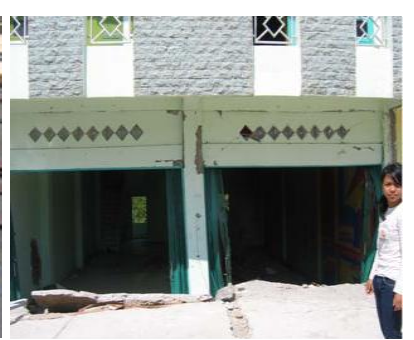

(b)
Figure 1. Soil Damages in Ratu Agung District due to the Bengkulu-Mentawai Earthquake on September 12, 2007 [8] (a) Crack at Ground Surface, (b) Massive Ground Failure

This paper presents the geophysical survey results in Ratu Agung District using the microtremor equipment. Microtremor is used to collect the information of ambient noise, and geophysical characteristic of sites, such as amplification $\left(A_{0}\right)$ and predominant frequency $\left(f_{0}\right)$. Furthermore, the analysis of seismic vulnerability $\left(K_{g}\right)$ and the possible ground damage defined as the ground shear strain $(\gamma)$ during the Bengkulu-Mentawai Earthquake in 2007. The results are then mapped into microzonation map in for Ratu Agung District. In general, this study is expected to provide a better understanding of seismic vulnerability to sites at Ratu Agung District during Bengkulu-Mentawai Earthquake. The results are also expected to consider and to warn the people in Ratu Agung District to implement the seismic hazard mitigation in Bengkulu City, especially once a strong earthquake happens in the future. For the stake holder, this study could contribute in design for spatial plan with the basis of seismic hazard assessment particularly in Bengkulu City.

\section{Study Area}

The study area is presented in Figure 2. Ratu Agung is a part of coastal areas in Bengkulu City. The district is directly facing the Indian Ocean. According to Hausler and Anderson [8], the huge damage during the Bengkulu-Mentawai Earthquake in 2007 (Earthquake epicentre is shown by the star symbol) were found in Ratu Agung District. This area is also dominated by alluvium materials, which included sands, clays, silts, and gravel. This area also has shallow ground water level. During the BengkuluMentawai Earthquake, the loose saturated sandy soils in 2007 could be liquefied, as reported by Hausler and Anderson [8].

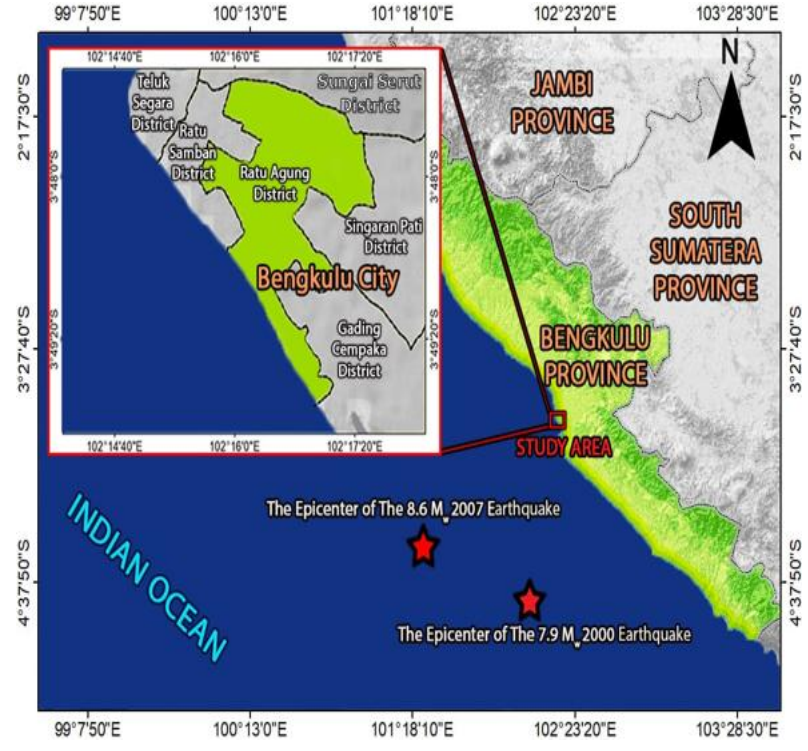

Figure 2. Location of Study Area

In line with the history of earthquake impact in Bengkulu City; therefore, Ratu Agung District is selected as the focused area in this study. In Ratu Agung District, several liquefaction evidences were also found [1,8] (as presented by circles in Figure 3). The site investigation on the basis of geophysical survey was performed in Ratu Agung District (Figure 3). This area is bordered with several districts, such as Sungai Serut District, Singaran Pati District, Ratu Samban District, and Gading Cempaka District. Ratu Agung District is dominated by formation of alluvium terraces deposits. This formation incudes sands, silts, clays, and gravels. A small part of reef limestone is also found in this study area. There are 32 sites (Figure 3) that were investigated in this study. The measurement using microtremor measurement is performed in this study area to obtain the information of geophysical characteristic such as the amplification and predominant frequency $\left(f_{0}\right)$.

\section{Theory and Method}

Ambient Noise Measurement by Microtremor and its Applicability

The ambient noise and its applicability have been widely observed by several researchers, such as Lachet et al. [9], El Hady et al. [10], and Mase et al. [11]. In the implementation, microtremor is applicable to observe the geophysical characteristic. The main interpretation results of microtremor measurement is the horizontal to vertical spectral ratio $(H / V$ ratio) corresponding to frequency (f). Mase et al. [11] mentioned that $H / V$ ratio also reflects the transfer function of ground site, which is addressed to estimate the predominant period $\left(T_{o}\right)$, the $H / V$ ratio, and the shear wave velocity $\left(V_{s}\right)$ profile. 


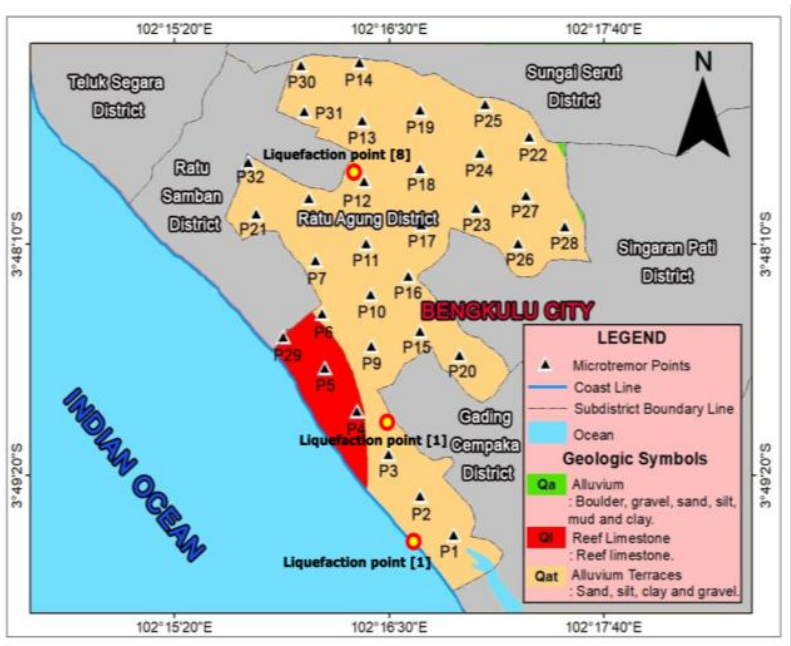

Figure 3. Layout of Site Investigation

Kanai and Tanaka [12] introduced the empirical technique to estimate the $H / V$ ratio of sites based on microtremor observation (popularised by Nakamura [13]). The method was derived based on the comparison of horizontal and vertical spectral ratio of the recorded ambient noise, which was aimed to expect $H / V$ ratio of sediment deposit during the recording of the ambient noise measurements. Atakan [14] noted that the $H / V$ ratio derived from the ambient noise measurement was consistent with the $H / V$ ratio of the earthquake recorded on between the surface of the sediments and the surface of bedrock (the interface between bedrock and the sediment deposit). Lachet and Bard [15] stated that the technical approach can depict the predominant frequency and result in the expected estimation of the site response of sediment soil deposits.

The example of interpretation of $H / V$ Ratio is presented in Figure 4. In Figure 4, the interpretation is presented on the comparison between the $H / V$ ratio and frequency (f). In Figure 4, there are three lines of $H / V$ curve, i.e. one solid line and two dashed lines. The solid line is the mean $H / V$ curve, whereas two dashed lines are the standard deviation lines of $H / V$ curve. The peak $H / V$ ratio values is defined as Amplification or $A_{0}$, whereas the frequency at $A_{0}$ is defined as predominant frequency. The $H / V$ ratio estimation of sites based on shear waves comparison on horizontal and vertical direction is expressed in the following equation,

$H / V=\sqrt{\frac{H_{(E W)}^{2}+H_{(N S)}^{2}}{2 V^{2}}}$

where, $H_{(E W)}$ and $H_{(N S)}$ are the horizontal spectral acceleration values in the east-west $(E W)$ and northsouth (NS) directions, respectively, and $V$ is the vertical spectral value.

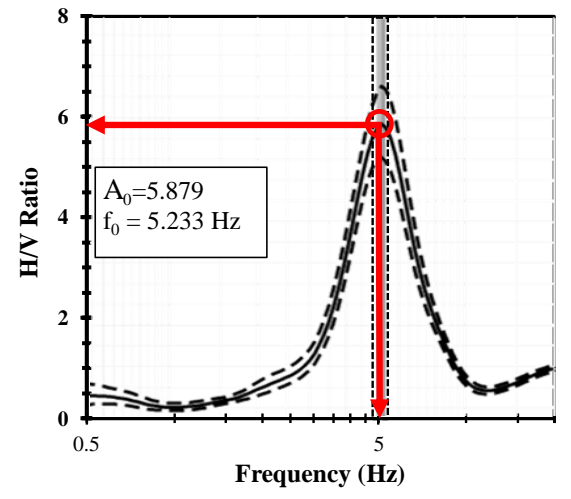

Figure 4. The Interpretation of Geophysical Properties at P11

The $H / V$ ratio were much more stable than the raw noise spectra, has been confirmed by many studies (Lachet et al. [9]; Koçkar and Akgün [16]). The $H / V$ ratio is normally well correlated with the predominant frequency $\left(f_{0}\right)$. Nevertheless, the peak $H / V$ ratio understanding is still the issue, which is frequently discussed in $H / V$ ratio determination aspect. Lachet and Bard [15] mentioned that the human noise and the environmental setting are usually restricted the valuable measurement to provide the best description of soil sites. Therefore, the $H / V$ ratio is possible to estimate the predominant frequency but it is not good enough to provide the $\mathrm{H} / \mathrm{V}$ ratio due to the constraint of velocity, Poisson's ratio ( $v$ ), and receiver restriction. BonnefoyClaudet et al. [17] suggested that due to the nature aspect and human noise; therefore, the $H / V$ ratio is not totally clarified. Raptakis et al. [18] stated that although the limitation of $H / V$ ratio reliability in term of local site perception, there is a consensus that predominant frequency values obtained from such measurement are reliable.

Based on this interpretation $H / V$ and predominant frequency $\left(f_{0}\right)$ can be easily obtained, as shown in circle in Figure 4. This information is possible to be used to determine the vulnerability indices $\left(K_{g}\right)$ in observed areas [19], which is expressed in this following equation,

$$
K_{g}=\frac{\left[(H / V)_{p e a k}\right]^{2}}{f_{0}}
$$

where, $K_{g}$ is vulnerability indices, $H / V_{\text {peak }}$ is peak of $H / V$ ratio, and $f_{o}$ is predominant frequency.

Nakamura [19] explained that shear strain at ground surface is unique parameter related to vulnerability indices. The shear strain value range and its resulted phenomena were compiled by Ishihara [20] (shown in Table 1). By following the strain dependences shown in Table 1, Nakamura [19] derived the formulation of $\gamma$ (shear strain) linked 
to $K_{g}$ which is shown in Equation 3. In its result, the estimation of shear strain is then referring to the limitation of shear strain presented in Table 1.

$$
\begin{aligned}
& \gamma=\frac{K_{g} a_{\max }}{\pi^{2} V_{b}} \\
& a_{\max }(\mathrm{gal})=\frac{5}{\sqrt{\mathrm{T}_{\mathrm{o}}}} 10^{\left.\left(0,61 \mathrm{M}_{\mathrm{w}}\right)-\left(1.66+\frac{3,60}{\mathrm{R}}\right) \operatorname{logR}+0.167-\frac{1,83}{\mathrm{R}}\right)}
\end{aligned}
$$

where, $\gamma$ is shear strain of soil dynamic properties, $K_{g}$ is vulnerability indices, $a_{\max }$ is acceleration of seismic wave at base rock (estimated by Kanai and Tanaka [21]) in Equation 4), and $V_{b}$ is shear wave velocity at base rock, $T_{0}$ is the predominant period (simply predicted by $\left.1 / f_{0}\right), \mathrm{M}_{\mathrm{w}}$ is the moment magnitude of earthquake, and $R$ is the hypocentre of earthquake

\section{Method of Research}

The framework of this study is presented in Figure 5. This study is initiated by collecting the information of earthquake history in Bengkulu Province. The literature review related to the geological condition and relevant studies related to the earthquake hazard in Bengkulu City. Furthermore, the study area is defined. The measurement using microtremor is performed to obtain the ambient noise, which is further processed to obtain $H / V$ ratio and predominant frequency $\left(f_{0}\right)$. The $H / V$ ratio and predominant frequency should fulfil the reliable $H / V$ curve as recommended by SESAME [22]. The values of $H / V$ Ratio and $f_{0}$ are then interpreted in microzonation map. Those values are also employed to analyse the seismic vulnerability indices $\left(K_{g}\right)$ for the study area. To observe the potential geotechnical hazard phenomenon during the Bengkulu-Mentawai Earthquake in 2007, the ground shear strain ( $\gamma)$ analysis is performed. In this study, the estimation of peak ground acceleration based on Kanai and Tanaka [21] model is performed. Both $K_{g}$ and $\gamma$ values on each site are depicted into microzonation map. In general, this study is expected to provide a better understanding of vulnerability aspects in Ratu Agung District during the Bengkulu-Mentawai Earthquake in 2007.

\section{Results and Discussion}

In this study, there are four maps are presented. The first one is microzonation map of $\mathrm{A}_{0}$, the second one is microzonation map of $f_{0}$. Both maps present the general interpretation of geophysical characteristic in Ratu Agung District. The third and the fourth microzonation maps are the microzonation map of $K_{g}$ and microzonation map of $\gamma$, respectively. Both $K_{g}$ and $f_{0}$ maps present the seismic vulnerability characteristic in the study area. The detail explanations of those maps are presented in the next following section.

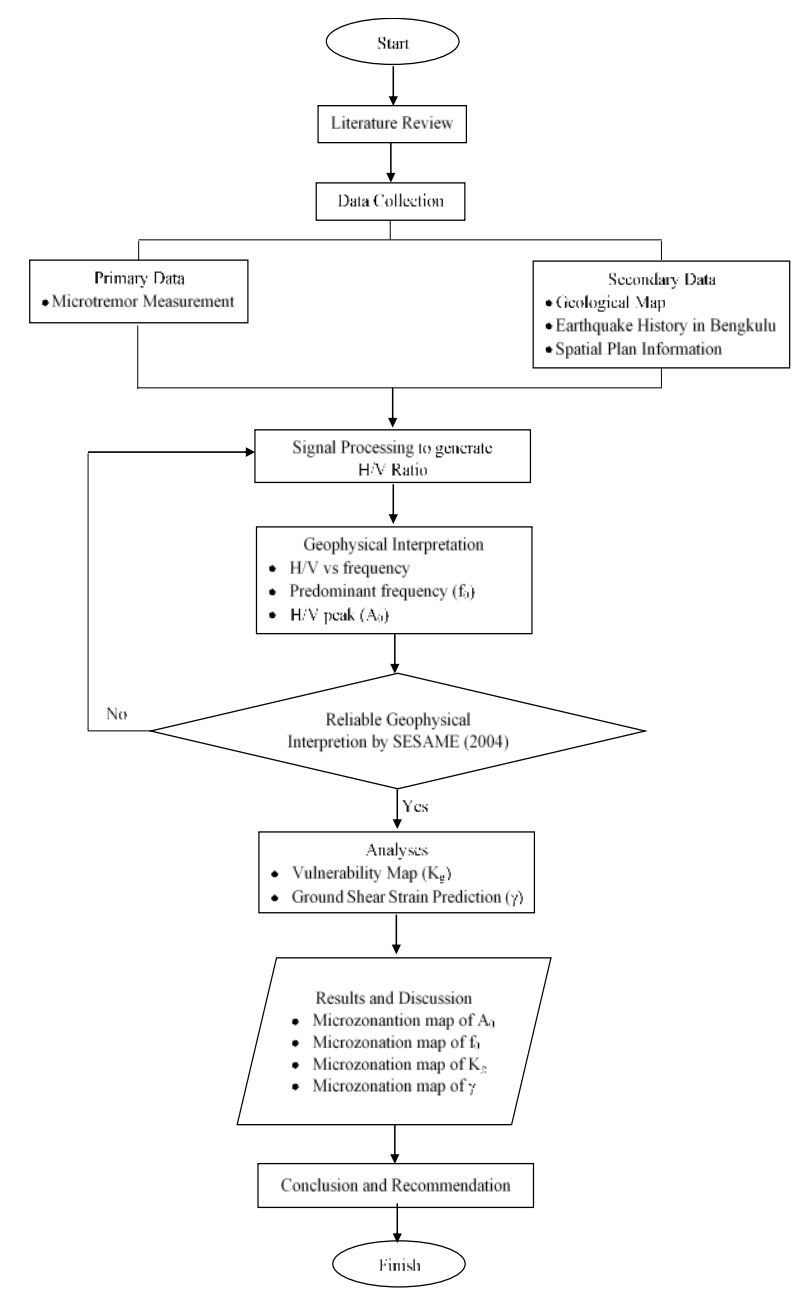

Figure 5. The Flow Chart of this Study

\section{Geophysical Characteristics}

In this study, the criterion based on SESAME [22] is used for Figure 6 presents the interpretation of $A_{0}$ and $f_{0}$ at the investigated sites. In general, Ratu Agung District has the $A_{0}$ ranging from 1.619 to 6.567, whereas $f_{0}$ ranges from 0.859 to $11.671 \mathrm{~Hz}$. On the basis of the results presented in Figure 7, there are several relatively high $A_{0}$ at low frequency (0.859 to $2 \mathrm{~Hz}$ ). A large $A_{0}$ with medium $\mathrm{f}_{0}(4.027$ to $7.427 \mathrm{~Hz})$ and high $f_{0}(8.368$ to $11.671 \mathrm{~Hz})$ is also observed in several measured sites. Although, the tendency is not well presented, the observation presents the evidence that generally, there is a large impedance contrast between sediment and bedrock in Ratu Agung District, especially for the sites with large $A_{0}$ and low $f_{0}$. It indicates that there is a large impedance contrast dominated by the thicker sediment underlain by a stiffer bedrock. On another hand, a high $f_{0}$ indicate that a relatively thin sediment would be underlain by the stiffer bedrock. This finding is also supported by Mase [2] and Refrizon et al. [4] studies which also reported that the thin sediment existed along coastal area of Bengkulu City, particularly Ratu Agung District 


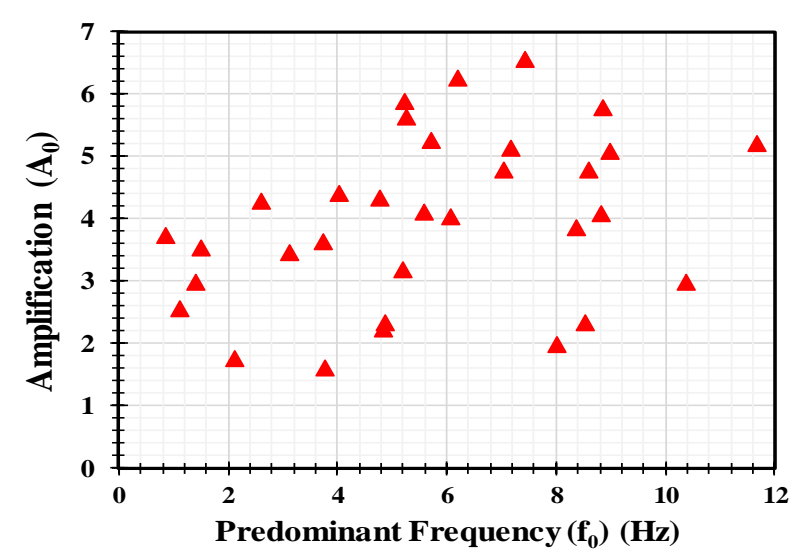

Figure 6. Amplification $\left(A_{0}\right)$ vs the Predominant Frequen$\operatorname{cy}\left(f_{0}\right)$

The interpretation of measurement results is presented in Figure 7. In this study, the criterion of SESAME [22] is used to generalize the characteristic of geophysical measurement results in the study area. Those results are also representing the areas in Ratu Agung District in Bengkulu City. Those selected sites are P1, P5, P11, P14, P22, and P32 (see Fig. 3). Figure 7a presents the $H / V$ curve for $\mathrm{P} 1$. Based on Figure 7a, it can be seen that there is a flattered $A_{0}$ values of 3.450 at $f_{0}$ of about $3.123 \mathrm{~Hz}$. It indicates that there is a medium impedance contrast in the site. According to SESAME [22], this site could be located at soft alluvium sediments and silty clay. In addition, the $H / V$ curve also predicted that the sediment is underlain by the sandstone bedrock. The two clear peaks at medium value of $f_{0}$ are presented by Figure $7 \mathrm{~b}$. The site has $A_{0}$ of 2.236 and $f_{0}$ of 4.833 $\mathrm{Hz}$, which means that there is a relatively small impedance contrast compared to the previous site. According to SESAME [22] and Gosar [23], this condition indicates that there are probably the deeper sediment deposits with relatively similar soil density. The clear peak has been observed at P11 and P14. P11 has the clear peak at relatively larger $f_{0}$, and vice versa for P14, as presented in Figure 7c and Figure $7 \mathrm{~d}$. These sites are likely located at elongated alluvial valley [22]. P11 exhibits that there is the impedance contrast resulted to the larger $A_{0}$ compared to P14. However, P14 tends to have thicker sediment compared to $\mathrm{P} 11$, since it has a smaller fo. Figure $7 \mathrm{e}$ and Figure $7 \mathrm{f}$ presents $H / V$ curve for P22 and P32. For P22, a clear peak has identified at predominant frequency of $2.589 \mathrm{~Hz}$, whereas P32 has a clear peak at predominant frequency of $7.990 \mathrm{~Hz}$. Based on the observation, P22 tends to have a thicker sediment compared to P32. This is due to the fact that $f_{0}$ of P32 is larger. However, P22 has potentially a larger impedance contrast among the layers in the sites compared to P32. This is indicated by a larger $A_{0}$ exhibited by P22. The two peaks of amplification are observed at P32 in which based on SESAME [22], they indicate two impedance contrasts in the surface. It is probably related to a denser sediment underlain by the shallower stiffer bedrock.

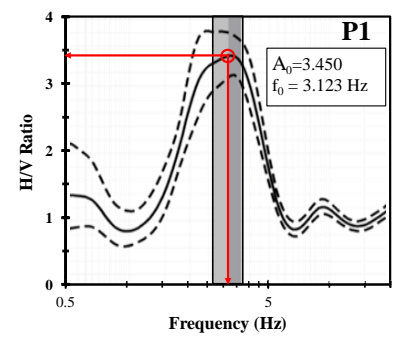

(a)

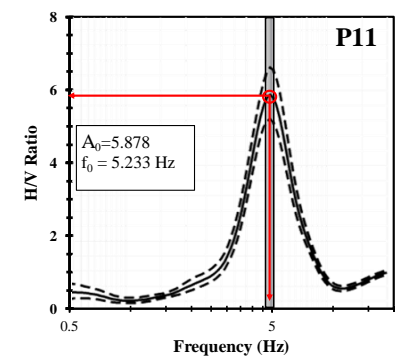

(c)

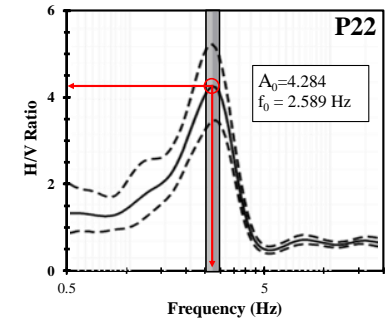

(e)

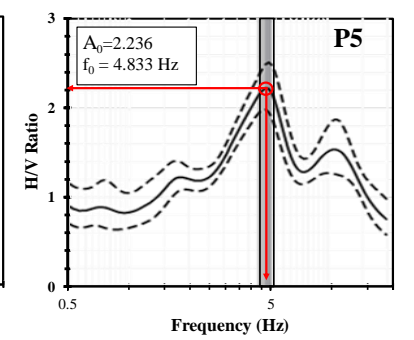

(b)

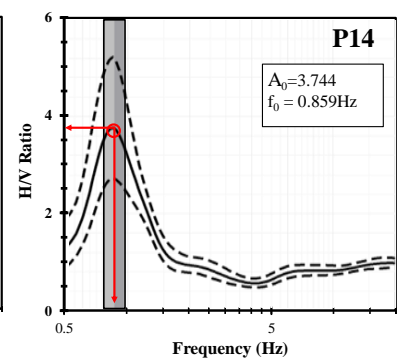

(d)

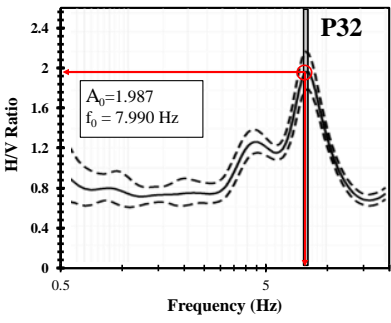

(f)
Figure 7. The H/V Ratio Corresponding to Frequency for (a) P1 (b) P5 (c) P11 (d) P14 (e) P22 and (f) P32

\section{Microzonation Map of $\mathrm{A}_{0}$}

The microzonation map of $A_{0}$ is presented in Figure 8. In this study, the Krigging Interpolation Method is implemented to generate microzonation map for Ratu Agung District. In general, Ratu Agung District sites have the dominant $A_{0}$ of about 3 to 5 , which are located in the middle part, northern part, and eastern part of Ratu Agung District. The middle part of Ratu Agung District, a higher $A$ o, i.e. about 5 to more than 6 , is found. In the western part, the $A_{0}$ values range from 1 to 3 are found. The larger amplification value indicates that there are the potential of wave amplifying due to the significant difference among the soil layers. This also presents that the propagated seismic wave could be larger, if it propagated from one medium to other soft mediums compared than the travelled previous wave. Gosar [24] also mentioned that the larger amplification could be caused due to the weak indication of relatively higher impedance contrast between the soft sediment and bedrock. Corresponding to the geological condition in the study area, Ratu Agung 
District is generally dominated by alluvium terraces composed by sands, silts, clays, and gravels. The larger $A_{0}$ sites reflects that the sites are dominated by the relatively loose or soft material near surface. For the site with the lower $A_{0}$, it means that there is no significant impedance contrast between the bedrock and soil deposits. It also indicates that the layers could be relatively having the similar density and consistency. This evidence is also confirmed by the geological condition in the western part in which there is the narrow zone of geological condition dominated by reef limestone. In this zone, the bedrock surface is relatively located at shallow depth [1]. Therefore, the propagated seismic wave is relatively smaller due to it travels in materials with the relatively similar densities. However, Mase [1] mentioned that those sites dominated by reef limestone formation could undergo resonance impact at medium to high period during seismic wave propagation of Bengkulu Mentawai Earthquake in 2007.

\section{Microzonation Map of $f_{o}$}

The interpretation of predominant frequency $\left(f_{0}\right)$ in the investigated sites is presented in microzonantion map in Figure 9. In general, Ratu Agung District has interval fo ranged from 1 to $11 \mathrm{~Hz}$. In the central area, $f_{0}$ values ranging from $5-8 \mathrm{~Hz}$. Gosar [23 and 24] mentioned that predominant frequency is associated with the sediment thickness in a study area. Regarding to the zonation, it indicates that the medium thick sediment thickness is potentially located in the central area. In the southern area and the northern area, the low fo $(1$ to $5 \mathrm{~Hz})$ exists. This indicates that there is a relatively thick alluvium deposit in Ratu Agung District. In the western part of Ratu Agung District and the eastern Part of Ratu Agung District and the small part of central Ratu Agung District, the higher predominant frequency ranging from 8 to more than $11 \mathrm{~Hz}$ are found in the study area. Corresponding to Gosar [23] and SESAME [23] recommendation, the site having the larger predominant frequency indicates that there is a relatively shallow bedrock. In another word, there is a relatively thin alluvium deposit in those zones.

Mase [1] mentioned that during the earthquakes, the liquefactions were found a long coastal area of Bengkulu City, including Ratu Agung. In connection with the predominant frequency $\left(f_{0}\right)$, along coastal area of Ratu Agung has $f_{0}$ of about 2 to $4 \mathrm{~Hz}$. It indicates that the relatively thick alluvium deposits composed by loose sand exist in that area. In addition, along coastal area of Ratu Agung also has $A_{o}$ up to 5. It also indicates that there is impedance contrast between sediment and bedrock in this area. Mase [2] reported that along coastal area of Bengkulu City could undergo the large ground amplification during earthquake. It gives the understanding that the thin sediment along coastal area of Bengkulu City tends to undergo the shaking effect during the earthquake. This could be the reason why the liquefaction was massively found along the coastal area.

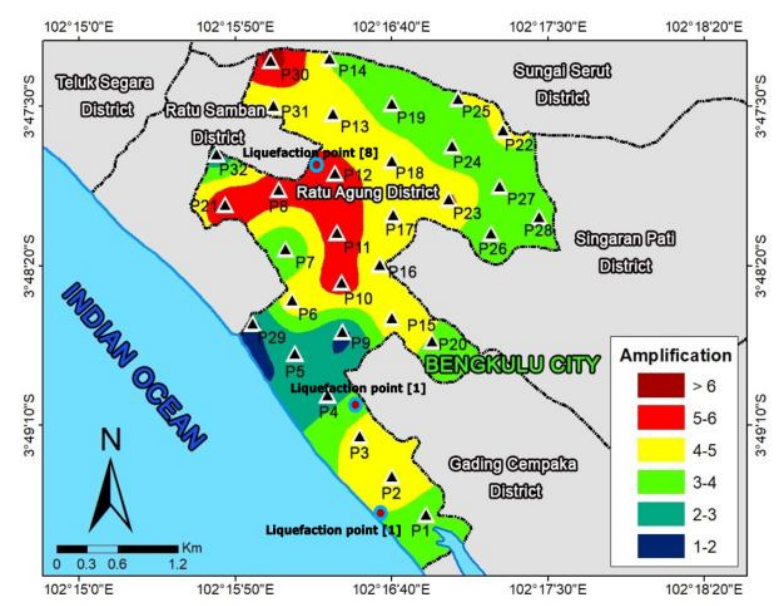

Figure 8. The Microzonation Map of Amplification $\left(A_{0}\right)$

\section{Microzonation Map of $\mathrm{K}_{\mathrm{g}}$}

Figure 10 presents the interpretation of seismic vulnerability index $\left(K_{g}\right)$ in Ratu Agung District. In Bengkulu City, $A_{0}$ and $f_{0}$ in the study area are relatively varied. Therefore, there is a variation of seismic vulnerability index. Seismic Vulnerability Index in Ratu Agung District ranges from 1 to 16. In majority, Ratu Agung Sites has the Seismic Vulnerability Index ranging from 1 to 4 , especially in the central part of Ratu Agung Area. Another dominant Seismic Vulnerability Index in Ratu Agung District has range of about 4 to 9 . These zonation ranges are spreading in several areas such as the eastern part of Ratu Agung District. The ranges of about 9 to 16 or more are detected in the small areas in Ratu Agung District. These ranges are located in the northern part of Ratu Agung District, which is bordered with Sungai Serut District. During the 2007 Bengkulu Mentawai Earthquake, Hausler and Anderson [8] reported that the studied area was massively liquefied. It seems to be consistent as resulted from this study, where in majority the $K_{g}$ values of about 2 to 9 are dominantly found in the study area. In general, the results of this study are relatively consistent as resulted from other studies performed in other areas, such as Babool in Iran and Yuanlin in Taiwan. Choobasti et al. [25] and Huang and Tseng [26] in studying the characteristic of liquefaction based on microtremor observation in Babol City and Yuanlin Areas, respectively. Choobasti et al. [25] showed that the minimum $K_{g}$ values of the liquefied site in Babol City was 5, whereas based on Huang and Tseng [26], the values of $K_{g}$ 
varied from 2 to 14 . The different values of $K_{g}$ from the result and other studies results may be caused by the difference of geological condition. The results of this study and other studies show that the vulnerability indices are not always well matched with the liquefaction damage. It means that the liquefaction event is possible to find on the location having the low vulnerability index, even though in the location with a high vulnerability index, liquefaction damage is more generally found [26].

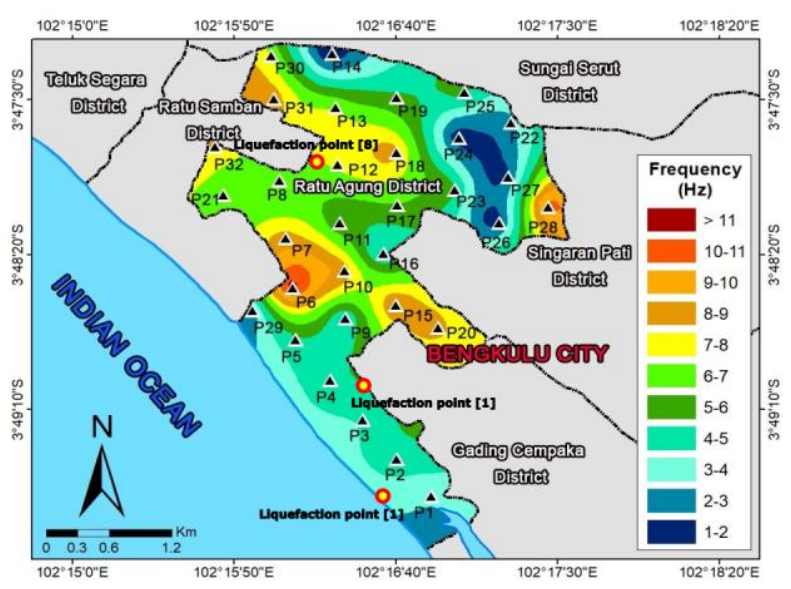

Figure 9. The Microzonation Map of $\mathrm{f}_{0}$

\section{Microzonation Map of $\gamma$}

In this study, the ground shear strain $(\gamma)$ that can interpret the possible geotechnical phenomenon during the $8.6 \mathrm{M}_{\mathrm{w}}$ Bengkulu-Mentawai earthquake in September 2007 are presented. As expressed in Equation 3, there is the acceleration variable, which is needed to estimate the ground shear strain. Therefore, the acceleration values estimated by Equation 4 is calculated. In this study, $V_{b}$ of $760 \mathrm{~m} / \mathrm{s}$ as shear wave velocity at base rock for Ratu Agung District is considered based on studies Mase [2] and Refrizon et al. [4]. The interpretation of acceleration microzonation during the Bengkulu-Mentawai Earthquake in 2007 for Ratu Agung District in is presented in Figure 11. In Figure 11, it can be seen that during the earthquake, the peak ground acceleration (PGA) mostly happened are ranging $0.5 \mathrm{~g}$ to more than $0.6 \mathrm{~g}$. This peak ground acceleration (PGA) are mostly found in the central, western, and eastern parts of Ratu Agung District. For several areas of Ratu Agung District, especially in the southern part and the northern part, PGA ranges from $0.2 \mathrm{~g}$ to $0.4 \mathrm{~g}$. Based on the interpretation of PGA in the study area, all areas in Ratu Agung District has undergone PGA more than 0.1g. According to Kramer [27], the minimum required PGA which is needed to trigger the liquefaction in an area is about $0.1 \mathrm{~g}$ with magnitude of earthquake of about $5 \mathrm{M}_{\mathrm{w}}$. The prediction of PGA in this study area seems to be consistent with massive liquefaction found in this location during the Bengkulu-Mentawai Earthquake 2007, since in in overall, the predicted PGA in the study area has exceeded the minimum requirement of PGA to trigger liquefaction.

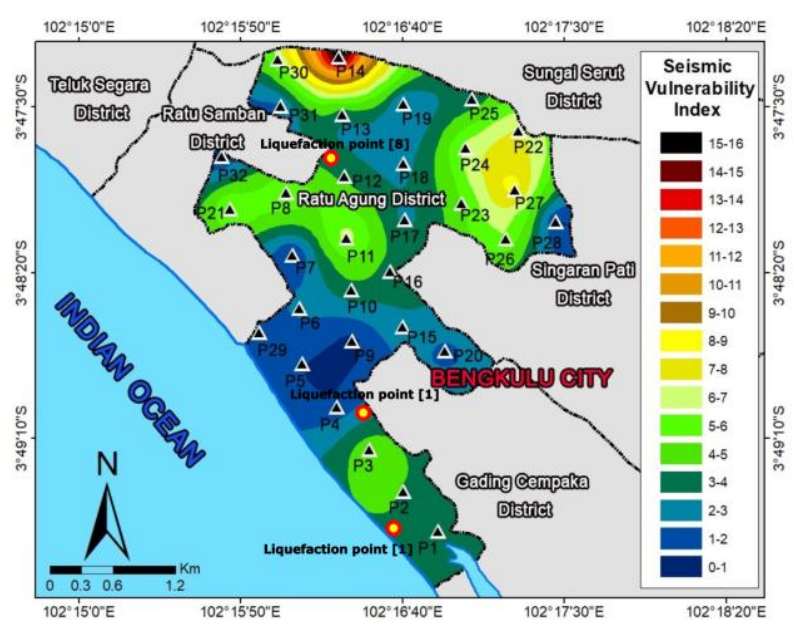

Figure 10. The Microzonation Map of $K_{g}$

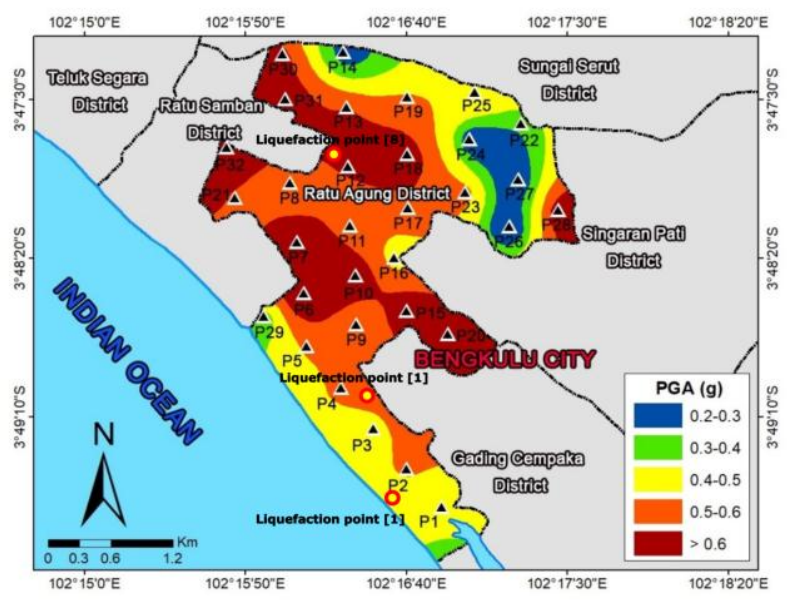

Figure 11. The Microzonation of Ground Shear Strain $(\gamma)$ in the Study Area.

From the interpretation of PGA presented in Figure 11, the ground shear strain can be estimated by Equation 3. The ground shear strain in the study area is presented in Figure 12. In general, the interpretation shows the ground shear strain in the location is of about $10^{-3}$. Based on the guidelines provided by Ishihara [20], the ground shear strain $(\gamma)$ reflected that in general, the possible damage during the Bengkulu-Mentawai Earthquake is Crack Settlement during the earthquake. Several evidences presented in Figure 1 have confirmed this possible settlement. The similar phenomenon such as cracks and fissures during the earthquake is also reported by several researchers such as Soralump and Feungaugsorn [28] and Lukkunaprasit et al. [29] during the Tarlay Earthquake in 2011 and the Mae Lao in Northern Thailand, respectively. Based on those reports, the crack settlement and fissures can 
happen due to the strong shaking resulted from earthquake. Those cracks and fissures are therefore able to be the path of excess pore water pressure to raise up. Those phenomena can be categorised as the one of sand boiling steps as stated by Castro [30 and 31]. Several areas in eastern and western parts of Bengkulu City could also undergo another phenomenon during the earthquake, which is known as wave vibration, since the ground shear strain resulted is about $10^{-4}$. In these wave vibration zones; the geological condition is dominated by denser materials and reef limestone at shallow depth. Those denser materials tend to reduce a worse possible impact during the earthquake. Therefore, only several locations in Ratu Agung District could undergo this phenomenon. In general, based on the interpretation of ground shear strain in Ratu Agung District, it can be concluded that the seismic damage during the earthquake is massively found.

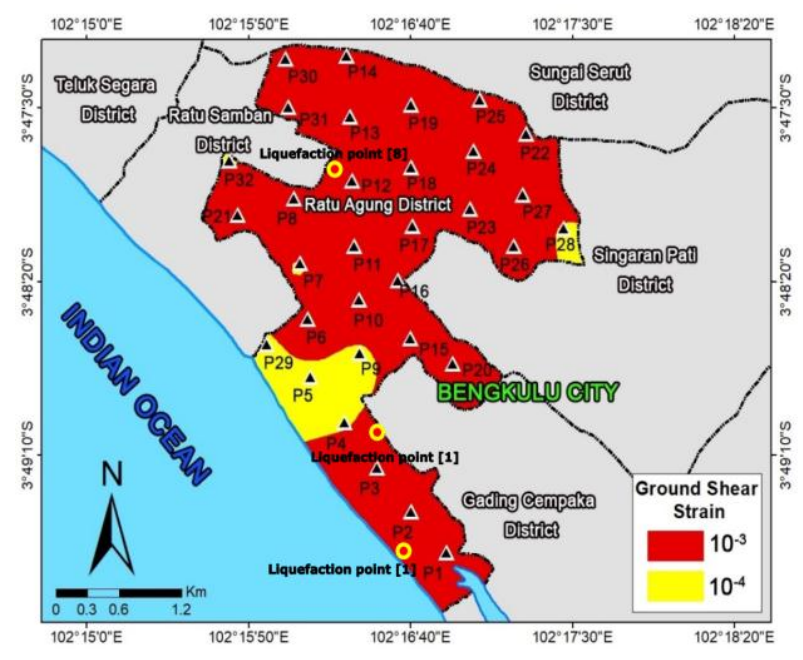

Figure 12. The microzonation of peak ground acceleration in the study area.

\section{Concluding Remarks}

This paper presents the seismic vulnerability during the Bengkulu-Mentawai Earthquake in 2007 in Ratu Agung District, Bengkulu City, one of the most impacted areas during the earthquake. The geophysical investigation on the sites using the ambient noise method of microtremor is presented. Several results such as the geophysical characteristic such as $H / V$ curves, $A_{0}$ microzonation map, $f_{0}$ microzonation map, PGA microzonation map, and the ground shear strain $(\gamma)$ are presented.

Ratu Agung District is detected as one of the most impacted areas during the Bengkulu-Mentawai Earthquake in 2007. Several field evidences had been reported by Hausler and Anderson [8]. The results of investigation present that there is a correlation between the geophysical condition and lique- faction phenomenon found during the BengkuluMentawai Earthquake. The $H / V$ curves show that the amplification $\left(A_{0}\right)$ in the sites are relatively larger. It indicates that there is the significant impedance contrast during the earthquake. It means that the possible impact of propagated wave amplification during the earthquake could be larger. The predominant period $\left(f_{0}\right)$ on the investigated sites are also relatively medium to small, which indicates the relatively thick sediments exist in the study area. Those sediments are mostly dominated by alluvium terraces (Qa) materials dominated by sands, clays, silts, and gravels. This geological condition seems to be one of the main reasons why the liquefaction could happen in this location. In addition, the shallow ground water level in the low terrain area such as Ratu Agung District could be another potentially trigger of liquefaction during the Bengkulu-Mentawai Earthquake as reported by Mase ([1 and 2]. The geophysical characteristic also derived a seismic vulnerability index $\left(K_{g}\right)$ in the study area. $K_{g}$ value in the study area is about 2 to 9 . Those values are relatively consistent with the study of Choobasti et al. [25] showed that the minimum $K_{g}$ values of the liquefied site in Babol City was 5, whereas on Huang and Tseng [26], the values of $\mathrm{K}_{\mathrm{g}}$ varied from 2 to 14 . The estimation of peak ground acceleration (PGA) to the site based on the geophysical characteristic shows that the PGA of Ratu Agung District during the Bengkulu-Mentawai earthquake has exceeded the minimum required PGA to trigger liquefaction, i.e. 0.1g [27]. In addition, as mentioned in Figure 2, the magnitude of the 2007 Bengkulu-Mentawai earthquake, i.e. $8.6 \mathrm{M}_{\mathrm{w}}$ has also fulfilled the minimum required PGA to trigger liquefaction. Therefore, the liquefaction during the Bengkulu-Mentawai Earthquake could happen in the study area. The ground shear strain estimation based on geophysical information and earthquake characteristic have shown that the crack settlement in the location can be mostly found during the earthquake. Hausler and Anderson [8] also reported that the crack settlement happened during the Bengkulu-Mentawai Earthquake. Those cracks could be a path during excess pore pressure built up and initiate the sand boiling in the study area. Those similar phenomena are also found by several researchers who observed the sand boiling initiated by the crack settlement as Soralump and Feungaugsorn [27] and Lukkunaprasit et al. [28] during the Tarlay Earthquake in the border of Thailand-Myanmar and the Mae Lao Earthquake in Chiang Rai, Northern Thailand. In general, the results of this study have led the recommendation to reconsider the possible earthquake impact in the future as well as a recommendation for the development of spatial plan for Ratu Agung District in particular and for Bengkulu City in general. 


\section{Acknowlegment}

The author would like to thank to the University of Bengkulu for the research funding. This research was supported by the Mandatory Research Fund Grant No. 3968/UN30.15/LT/2018 and the competitive research fund in 2019 from the University of Bengkulu.

\section{References}

1. Mase, L.Z., One Dimensional Site Response Analysis of Liquefaction Potential along Coastal Area of Bengkulu City, Indonesia, Civil Engineering Dimension, 20(2), 2018, pp. 57-69.

2. Mase, L.Z., Reliability Study of Spectral Acceleration Designs Against Earthquakes in Bengkulu City, Indonesia, International Journal of Technology, 9(5), 2018, 910-924.

3. Farid, M. and Hadi, A.I., Measurement of Shear Strain in Map Liquefaction Area for Earthquake Mitigation in Bengkulu City, Telkomnika, 16(4), 2018, pp. 1597-1606.

4. Refrizon, Hadi, A.I., Lestari, K., and Octari, T., Analysis of Peak Ground Acceleration and Seismic Vulnerability in Ratu Agung Bengkulu City, In: Proceeding of Semirata FMIPA UNILA, Lampung, 10-12 May, 2013, Indonesia (in Indonesian)

5. Mase, L.Z., Earthquake Characteristic in Bengkulu City, Teknosia, 2(15), 2015, pp. 25-34. (in Indonesian).

6. Mase, L.Z., and Somantri, A.K., Liquefaction Potential Analysis in Lempuing Sub-District Based on the Critical Peak Ground Acceleration, Potensi, 25(1), 2016, pp. 1-11.

7. Mase, L.Z., Liquefaction Potential Analysis Along Coastal Area of Bengkulu Province due to the 2007 Mw 8.6 Bengkulu Earthquake, Journal of Engineering and Technological Sciences, 49(6), 2017, pp. 721-736.

8. Hausler, E. and Anderson, A., Observation of the 12 and 13 September 2007 Earthquake, Sumatra, Indonesia. Build Change Report, Denver, Colorado, USA, 2007.

9. Lachet, C., Hatzfeld, D., Bard, P. Y., Theodulidis, N., Papaioannou, C., and Savvaidis, A., Site Effects and Microzonation in the City of Thessaloniki (Greece) Comparison of Different Approaches, Bulletin of the Seismological Society of America, 86(6), 1996, pp.1692-1703.

10. El-Hady, S., Fergany, E.A.A., Othman, A., and Mohamed, G.E.A., Seismic Microzonation of Marsa Alam, Egypt using Inversion HVSR of Microtremor Observations, Journal of Seismo$\log y$, 16(1), 2012, pp. 55-66.

11. Mase, L.Z., Likitlersuang, S., Tobita, T., Chaiprakaikeow, S., and Soralump, S., Local Site
Investigation of Liquefied Soils Caused by Earthquake in Northern Thailand, Journal of Earthquake Engineering, 2018, pp.1-24. (online first)

12. Kanai, K. and T. Tanaka., Measurement of the Microtremor, Bulletin of Earthquake Research Institute, 32(1), 1954, pp. 199-209.

13. Nakamura, Y., A Method for Dynamic Characteristics Estimation of Subsurface using Microtremor on the Ground Surface, Railway Technical Research Institute: Quarterly Reports, 30(1), 1989, pp. 25-33.

14. Atakan, K, The Need for Standardized Approach for Estimating the Local Site Effects based on Ambient Noise Recordings, In: Mucciarelli, M, Herak, M, Cassidy, J.F., Editors, Proceeding of the NATO Advanced Research Workshop on Increasing Seismic Safety by Combining Engineering Technologies and Seismological Data, Dubrounik, Croatia 19-21 September 2007: The NATO Science for Peace and Security Series-C: Environmental Security, XVIII. pp 3-15, 2009.

15. Lachet, C. and Bard, P.Y., Numerical and Theoretical Investigations on the Possibilities and Limitations of Nakamura's Technique, Physics of the Earth, 42(1), 1994, pp. 377-397.

16. Koçkar, M.K. and Akgün, H. (2012), Evaluation of the Site Effects of the Ankara Basin, Turkey, Journal of Applied Geophysics, 83(1), 2012, pp. 120-134.

17. Bonnefoy-Claudet, S., Cornou, C., Bard, P.Y., Cotton, F., Moczo, P., Kristek, J., and Fah, D., $\mathrm{H} / \mathrm{V}$ ratio: A Tool for Site Effects Evaluation, Results from 1-D Noise Simulations, Geophysical Journal International, 167(2), 2006, pp. 827837.

18. Raptakis, D.G., Manakou, M.V., Chavez-Garcia, F.J., Makra, K.A., and Pitilakis, K.D., 3D Configuration of Mygdonian Basin and Preliminary Estimate of its Site Response, Soil Dynamics and Earthquake Engineering, 25(1), 2005, pp. 871-887.

19. Nakamura, Y., Seismic Vulnerability Indices for Ground and Structures using Microtremor, In: Proceeding of World Congress on Railway Research in Florence, Italy, 16-19 November, 1997. pp. 1-7.

20. Ishihara, K., Introduction to Dynamic Soil Mechanism, University of Tokyo, 1978. (in Japanese)

21. Kanai, K., and Tanaka, T., On Microtremor VIII, Bulletin of the Earthquake Research Institute, University of Tokyo, 39(1), 1961, pp. 97-114.

22. SESAME., Guidelines for the Implementation of H/V Spectral Ratio Technique on Ambient Vibrations: Measurements, Processing, and Interpretations, European Commission - Research General Directorate Project No. EVG1-CT-200000026, SESAME, 2004. 
23. Gosar, A., Study on the Applicability of the Microtremor HVSR Method to Support Seismic Microzonation in the Town of Idrija (W Slovenia). Natural Hazards and Earth System Sciences, 17(6), 2017, pp. 925-937.

24. Gosar, A., Site Effects and Soil-Structure Resonance Study in the Kobarid Basin (NW Slovenia) using Microtremors, Natural Hazards and Earth System Sciences, 10(4), 2010, pp.761-772.

25. Choobasti, A.J., Naghizadehrokni, M., and Rezaei, S., Liquefation Assesment by Microtremor Measurements in Babol City, the $5^{\text {th }}$ International Conference on Geotechnique, Construction Materials, and Environmental, Osaka, Japan, 16-18 Nov, 2015.

26. Huang, H.C. and Tseng, Y.S., Characteristic of Soil Liquefaction using $\mathrm{H} / \mathrm{V}$ of Microtremors in Yuanlin Area, Taiwan, Terrestrial, Atmospheric, and Oceanic (TAO) Science Journal, 13(3), 2002, pp. 325-338.
27. Kramer, S.L., Geotechnical Earthquake Engineering, Prentice Hall, New Jersey, USA, 1996.

28. Soralump, S., and Feungaugsorn, J., Probabilistic Analysis of Liquefaction Potential: The First Eyewitness Case in Thailand, In: the 18 th National Convention of Civil Engineering, Chiang Mai, Thailand, 8-10 May, 2013, pp. 301-307.

29. Lukkunaprasit, P., Ruangrassamee, A., Boonyatee, T., Chintanapakdee, C., Jankaew, K., Thanasisathit, N., and Chandrangsu, T., Performances of Structures in the $\mathrm{M}_{\mathrm{w}}$ 6.1 Mae Lao Earthquake in Thailand on May 5, 2014 and Implication for Future Construction, Earthquake Engineering, 20(2), 2016, pp. 219-242.

30. Castro, G., Empirical Methods in Liquefaction Evaluation, Proceedings of the $1^{\text {st }}$ Annual Leonardo Zeevaert International Conference, Mexico City, Mexico, November, 1985. pp. 1-41.

31. Castro, G., On the Behavior of Soils during Earthquakes-Liquefaction, Developments in Geotechnical Engineering, 42(1), 1987, pp. 169-204. 